\title{
RESVERATROL AND PTEROSTILBENE POTENTLY INHIBIT SARS-COV-2 REPLICATION IN VITRO
}

Bram M. ter Ellen ${ }^{\mathrm{a} *}$, Nilima Dinesh Kumara, ${ }^{\mathrm{a} *}$, Ellen M. Bouma*, Berit Troost ${ }^{\mathrm{a}}$, Denise P.I. van de Pol $^{\mathrm{a}}$, Heidi H. van der Ende-Metselaar ${ }^{\mathrm{a}}$, Leonie Apperloo ${ }^{\mathrm{c}}$, Djoke van Gosliga ${ }^{\mathrm{d}}$, Maarten van den Berge ${ }^{e}$, Martijn C. Nawijn ${ }^{\mathrm{c}}$, Peter H.J. van der Voort ${ }^{\mathrm{f}}$, Jill Moser ${ }^{\mathrm{f}}$, Izabela A. Rodenhuis-Zybert ${ }^{\mathrm{a}}$, Jolanda M. Smit ${ }^{\text {a\# }}$

*Contributed equally

${ }^{\text {a }}$ Department of Medical Microbiology and Infection Prevention, University Medical Center Groningen, University of Groningen, 9700 RB Groningen, The Netherlands.

${ }^{\mathrm{b}}$ Department of Biomedical Sciences of Cells \& Systems, University Medical Center Groningen, University of Groningen, 9700 RB Groningen, The Netherlands

${ }^{c}$ Department of Pathology and Medical Biology, University of Groningen, University Medical Center Groningen, GRIAC Research Institute, 9700 RB Groningen, The Netherlands

d Department of Pediatrics, Beatrix Children's Hospital, University Medical Center Groningen, University of Groningen, GRIAC Research Institute, 9700 RB Groningen, The Netherlands.

${ }^{\mathrm{e}}$ Department of Pulmonary Diseases, University Medical Center Groningen, University of Groningen, GRIAC Research Institute, 9700 RB Groningen, The Netherlands.

${ }^{\mathrm{f}}$ Department of Critical Care, University Medical Center Groningen, University of Groningen, 9700 RB Groningen, The Netherlands.

\# corresponding author

Jolanda M. Smit

Department of Medical Microbiology and Infection Prevention

Hanzeplein 1 - HPC EB80

Postbus 30.001

9700 RB Groningen

The Netherlands

Jolanda.smit@umcg.nl 


\begin{abstract}
The current COVID-19 pandemic is caused by severe acute respiratory syndrome coronavirus 2 (SARS-CoV-2) and has an enormous impact on human health and economy. In search for therapeutic options, researchers have proposed resveratrol, a food supplement with known antiviral, anti-inflammatory and anti-oxidant properties as an advantageous antiviral therapy for SARS-CoV-2 infection. Here, we provide evidence that both resveratrol and its metabolically more stable structural analog, pterostilbene, exhibit potent antiviral properties against SARS-CoV-2 in vitro. Resveratrol and pterostilbene showed antiviral activity in African green monkey kidney cells and in human primary bronchial epithelial cells cultured in an air-liquid interface system. Both compounds actively inhibit virus replication within infected cells as reduced virus progeny production was observed when the compound was added at postinoculation conditions. Without replenishment of the compound, antiviral activity was observed up to roughly 5 rounds of replication, demonstrating the long-lasting effect of these compounds. Collectively, our data indicate that resveratrol and pterostilbene are promising antiviral compounds to treat SARS-CoV-2 infection. Because these results represent laboratory findings in cells, we advocate evaluation of these compounds in clinical trials before statements are made whether or not these drugs are advantageous for COVID-19 treatment.
\end{abstract}

\title{
Key words
}

Resveratrol; Pterostilbene; SARS-CoV-2; Antiviral; Human primary bronchial epithelial cells

\section{Introduction}

Within less than a year, the novel severe acute respiratory syndrome coronavirus 2 (SARSCoV-2) has infected over 56 million people and over 1.3 million individuals have succumbed to SARS-CoV-2 infection worldwide (John Hopkins university and medicine, 2020). Infection with SARS-CoV-2 leads to a wide range of manifestations ranging from an asymptomatic infection to a self-limiting mild disease to a potentially fatal disease. It is estimated that approximately $15 \%$ of the infected individuals develop severe pneumonia and about $5 \%$ develop an acute respiratory distress syndrome (ARDS), septic shock and/or multiple organ failure. Severe disease is a consequence of lung inflammation and damage caused by direct viral infection of the lung and/or by the immune response triggered to control virus dissemination (2-4). To prevent and treat SARS-CoV-2 infection, vaccines and antiviral drugs are urgently needed.

The natural compounds resveratrol (trans-3,5,4'-trihydroxystilbene) and the structurally related pterostilbene (trans-3,5-dimethyoxy-4'-hydroxystilbene) share multiple bioactivities which are potentially beneficial for human health $(5,6)$. In recent years, resveratrol was described to exhibit antiviral activity towards a large number of viruses including human immunodeficiency virus (7), influenza virus (8), respiratory syncytium virus (9), as well as, Middle East respiratory syndrome coronavirus (MERS-CoV) (10). In most cases, resveratrol was found to directly interfere with viral replication (11). Next to the direct effect on virus replication, resveratrol was also reported to exhibit anti-inflammatory and anti-oxidant properties thereby having the potential to mitigate virus-induced disease pathogenesis $(11,12)$. Based on these findings, we 
and others have postulated that resveratrol and its structural analog might be an advantageous treatment option for SARS-CoV-2 infected individuals (13-15).

In this study, we examined the efficacy of resveratrol and pterostilbene on suppression of viral replication in several in vitro models of SARS-CoV-2 infection. Specifically, we used African green monkey kidney cells (Vero E6), human lung epithelial cells (Calu-3), and human primary bronchial epithelial cells (PBECs) differentiated on air-liquid interface (ALI) cultures. To delineate the mode-of-action, we assessed the effect of the compounds when added prior to, during, and after virus cell entry had been established. The antiviral effect was also evaluated over time to assess the long-lasting effect of the compounds.

\section{Material and methods}

\section{Compounds}

99\% trans-resveratrol was obtained from Bulkpowders and dissolved in absolute ethanol $(\mathrm{EtOH})$ obtaining a stock solution of $100 \mathrm{mM}$ which was used in the experiments. Pterostilbene 97\% HPLC determined (Sigma Aldrich) was dissolved in absolute EtOH obtaining a stock solution of $10 \mathrm{mM}$ which was used in the experiments. The EtOH concentration was below 0.6 $\%$ in all infection experimental conditions.

\section{Cell culture and differentiation}

The African green monkey Vero E6 cell line (ATCC CRL-1586) was maintained in Dulbecco's minimal essential medium (DMEM) (Gibco), high glucose supplemented with $10 \%$ fetal bovine serum (FBS) (Life Science Production), penicillin $(100 \mathrm{U} / \mathrm{mL})$, and streptomycin $(100 \mathrm{U} / \mathrm{mL})$ (Gibco). The human lung epithelial cell line Calu-3 (ATCC HTB-55) was maintained in DMEM F-12 (Lonza) supplemented with 10\% FBS, 1\% Glutamax (Thermofisher), 1\% non-essential amino acid (Thermofisher), penicillin $(100 \mathrm{U} / \mathrm{mL})$, and streptomycin $(100 \mathrm{U} / \mathrm{mL})$. All cells were mycoplasma negative and maintained at $37^{\circ} \mathrm{C}$ under $5 \% \mathrm{CO}_{2}$. PBECs were cultured from bronchial bushing obtained by fibreoptic bronchoscopy performed using a standardized protocol during conscious sedation $(16,17)$. The medical ethics committee of the University Medical Center Groningen approved the study, and all subjects gave their written informed consent. The donors were 2 male and 2 female non-smoking healthy control volunteers (less than 2.5 packyears) with no history of respiratory disease aged 49-62. PBECs were cultured and fully differentiated under ALI conditions in transwell inserts, as previously described (18).

\section{SARS-CoV-2 production and characterization}

The SARS-CoV-2 strain NL/2020 was obtained from European Virus Archive global (EVAg 010V-03903). The original stock was passaged twice in Vero E6 cells to obtain a working stock. Infectious virus titers were determined by plaque assay on Vero E6 cells and defined as the number of plaque forming units (PFU) per mL. Briefly, Vero E6 cells were seeded at a density of $1.3 \times 10^{5}$ cells/well in a 12 -well plate format. At $24 \mathrm{hr}$ post-seeding, cells were infected with 10 -fold serial dilutions of the sample in duplo. At $2 \mathrm{hr}$ post inoculation (hpi), wells were 
overlaid with $1 \%$ seaplaque agarose (Lonza) prepared in 2x MEM. Plaques were counted at 44 hpi. One plaque in the lowest dilution corresponds to $150 \mathrm{PFU} / \mathrm{mL}$ and was set as the detection limit of the assay.

\section{Cytotoxicity assays}

\section{MTS}

In the context of Vero E6 and Calu-3 cells, cells were exposed to increasing concentrations of resveratrol and pterostilbene for $8 \mathrm{hr}$. Subsequently, cellular cytotoxicity was evaluated using the CellTiter 96® AQueous One Solution Cell Proliferation Assay kit using manufacturer's instructions from Promega. Briefly, cells were seeded in a 96-well plate at a density of $1 \times 10^{4}$ cells/well. At $24 \mathrm{hr}$ post-seeding, Vero E6 cells were treated with increasing concentrations of resveratrol and pterostilbene ranging from 2 to $250 \mu \mathrm{M}$ or the equivalent volumes of EtOH for $8 \mathrm{hr}$ at $37^{\circ} \mathrm{C}$. Calu-3 cells were treated with 50 to $150 \mu \mathrm{M}$ resveratrol, 40 or $60 \mu \mathrm{M}$ pterostilbene or the equivalent volumes of EtOH for $8 \mathrm{hr}$ at $37^{\circ} \mathrm{C}$. At $8 \mathrm{hr}$ post-treatment, $20 \mu \mathrm{lof}$ MTS/PMS solution was added per well and incubated for $2 \mathrm{hr}$ at $37^{\circ} \mathrm{C}$. Subsequently, $10 \%$ SDS was added to each well ( $2 \%$ end concentration) to stop the reaction and the absorbance was measured at $490 \mathrm{~nm}$ with a microplate reader. Values are displayed as percentage compared to normalized non-treated (NT) control. All individual experiments were performed in triplicate.

\section{Live death staining flow cytometry}

PBECs were exposed to $150 \mu \mathrm{M}$ resveratrol and $60 \mu \mathrm{M}$ pterostilbene at the basolateral side for $48 \mathrm{hr}$ at $37^{\circ} \mathrm{C}$, and subsequently harvested and stained with fixable viability dye eFluor 780 for $20 \mathrm{~min}$ at $4^{\circ} \mathrm{C}$. After staining cells were washed in FACS buffer (PBS, 2\% FBS, 5 mM EDTA), centrifuged and subsequently fixed with $4 \%$ PFA for $10 \mathrm{~min}$ at $4{ }^{\circ} \mathrm{C}$. After fixation, cells were washed, centrifuged, and resuspended in FACS buffer. Cells were analyzed for viability with the LSR-2 flow cytometer (BD Bioscience). Data was analyzed using Kaluza software (Beckman Coulter).

\section{$L D H$}

PBECs were exposed to $150 \mu \mathrm{M}$ resveratrol and $60 \mu \mathrm{M}$ pterostilbene at the basolateral side for $48 \mathrm{hr}$ at $37^{\circ} \mathrm{C}$. After incubation, apical sides of the inserts were incubated with medium for 30 min at $37^{\circ} \mathrm{C}$. The apical wash was collected and centrifuged $2000 \mathrm{x}$ g at $4^{\circ} \mathrm{C}$ to clear from cell debris. The commercially available kit (ThermoFisher, CyQUANT ${ }^{\mathrm{TM}}$ LDH Cytotoxicity Assay Kit) was used according to manufacturer protocol. The absorbance was measures at 490 and $680 \mathrm{~nm}$ using a microplate reader. $680 \mathrm{~nm}$ absorbance OD values (background) were subtracted from $490 \mathrm{~nm}$ OD values. Cytotoxicity was calculated using the following formula:

$$
\% \text { cytotoxicity }=\frac{(O D \text { Compound treated } L D H \text { activity }-O D \text { spontaneous } L D H \text { activity })}{(O D \text { maximum } L D H \text { activity }-O D \text { spontaneous activity })}
$$

\section{Antiviral assay in Vero E6 and Calu-3 cells}


Vero E6 cells were seeded at a density of $1.3 \times 10^{5}$ cells/well in 12-well plates and Calu-3 cells were seeded at a density of $2 \times 10^{5}$ cells/well in 24 -well plates. Cells were infected with SARSCoV-2 at a multiplicity of infection (MOI) 1 and treated with increasing concentrations of resveratrol and pterostilbene or the equivalent volumes of EtOH corresponding to the highest concentration of compound for $2 \mathrm{hr}$ at $37^{\circ} \mathrm{C}$. Infection was done in $250 \mu \mathrm{l}$ DMEM (2\% FBS) medium. After infection, virus inoculum was removed, cells were washed twice with plain DMEM media, and fresh DMEM 10\% FBS containing the compound or the equivalent volumes of EtOH was added after which incubation was continued. Cell supernatant was collected at 8 hpi, centrifuged to clarify from cell debris and the viral titer was determined using plaque assay. For the durability assay, Vero E6 cells were infected with SARS-CoV-2 at MOI 0.01 and treated with $150 \mu \mathrm{M}$ resveratrol or $60 \mu \mathrm{M}$ pterostilbene or the equivalent volume of EtOH as indicated above. Supernatants were collected at 16, 24, 40 and 60 hpi and analyzed as above.

\section{Antiviral assay in primary bronchial epithelial cells}

After 3 weeks culture under ALI conditions, cells were washed once with 1:1 plain DMEM and Airway Epithelial Cell Growth medium (Promocell) supplemented with BSA and supplement kit (ALI culture medium, Promocell), and inoculated with SARS-CoV-2 at MOI 5 at the apical side. At the time of infection, 75 or $150 \mu \mathrm{M}$ resveratrol, $60 \mu \mathrm{M}$ pterostilbene or the equivalent volumes of EtOH were added at the basolateral side of the insert in ALI culture medium . At 2 hpi, cells were washed twice with OptiMEM (Gibco) at the apical side and incubation was continued on air at $37{ }^{\circ} \mathrm{C}$. Thirty min prior to harvesting (12, 24 and 48 hpi), OptiMEM was added to the apical side of the ALI cultures. At the time of harvest, the apical supernatant and $150 \mu \mathrm{l}$ of basolateral medium was harvested. At the basolateral side, after each harvest new ALI culture media containing the compound or EtOH was added. The viral titer in the apical supernatant was determined using plaque assay.

\section{Time-of-drug-addition assay}

For the time-of-drug-addition experiments, the cells were treated with $150 \mu \mathrm{M}$ resveratrol or $60 \mu \mathrm{M}$ pterostilbene at pre, during, or post-inoculation conditions. For the pre-inoculation condition, cells were incubated with the compounds or the equivalent volume of EtOH for $2 \mathrm{~h}$. At the time of infection, cells were washed three times before the addition of the virus inoculum. For the during condition, the compounds or the equivalent volumes EtOH were added together with the virus inoculum and was present for $2 \mathrm{hr}$. At $2 \mathrm{hpi}$, cells were washed three times with plain DMEM, fresh DMEM 10\% FBS was added, and incubation was continued. For the postinoculation conditions, the compounds or the equivalent volumes $\mathrm{EtOH}$ were added to the cell culture medium after removal of the virus inoculum. All supernatants were collected 8 hpi, centrifuged to clarify from cell debris and subjected to plaque assay to determine the viral titer.

\section{Virucidal assay}

$2.5 \times 10^{5}$ PFU of SARS-CoV-2 were incubated in $300 \mu 1$ DMEM $2 \%$ FBS in the presence or absence of $150 \mu \mathrm{M}$ resveratrol, $60 \mu \mathrm{M}$ pterostilbene or the equivalent volume of EtOH for $2 \mathrm{hr}$ at $37^{\circ} \mathrm{C}$. Subsequently, viral titer was determined by plaque assay. 


\section{Statistical analysis}

All data is represented as mean \pm SEM. The concentration that reduced virus particle production by 50 and $90 \%$ is referred to as EC50 and EC90, respectively. Dose-response curves were fitted by non-linear regression analysis employing a sigmoidal model. All data was analyzed in GraphPad Prism 8 software. Non-paired two-tailed Student T test was used to evaluate statistical differences and a $\mathrm{p}$ value $\leq 0.05$ was considered significant with $* \mathrm{p} \leq 0.05, * * \mathrm{p} \leq$ 0.01 and $* * * \mathrm{p} \leq 0.001$ and NS as non-significant.

\section{Results}

\section{Resveratrol and pterostilbene inhibit SARS-CoV-2 infection in Vero E6 cells}

Prior to assessing antiviral activity of resveratrol and pterostilbene, we determined the cellular cytotoxicity of the compounds in Vero E6 cells. We observed a dose-dependent cytotoxic effect of both resveratrol and pterostilbene (Fig. S1A,B). Limited cytotoxicity was observed up to a concentration of $200 \mu \mathrm{M}$ resveratrol and $100 \mu \mathrm{M}$ pterostilbene. At these conditions, no cytotoxicity was observed for the solvent control EtOH. However, the cells treated with compound appeared to be stressed based on morphology and therefore we decided to use 150 $\mu \mathrm{M}$ resveratrol and $60 \mu \mathrm{M}$ pterostilbene as the highest concentration in follow-up experiments. Next, we investigated the antiviral effect of resveratrol and pterostilbene during infection with SARS-CoV-2 (isolate NL/2020). Vero E6 cells were inoculated with SARS-CoV-2 (MOI 1) in the presence of increasing concentrations of resveratrol, pterostilbene or an equivalent volume of EtOH corresponding to the highest concentration of the compound. Resveratrol and pterostilbene showed a dose-dependent antiviral effect on SARS-CoV-2 infection in Vero E6 cells (Fig. 1A,B). No effect on infectious virus production was observed for the EtOH solvent control. Subsequent non-linear regression analyses revealed that virus particle production is reduced by $50 \%$ (EC50) at a concentration of $66 \mu \mathrm{M}$ resveratrol and $19 \mu \mathrm{M}$ pterostilbene (Fig. 1C). Furthermore, $90 \%$ reduction (EC90) of virus progeny is observed at a concentration of 119 $\mu \mathrm{M}$ resveratrol and $47 \mu \mathrm{M}$ pterostilbene (Fig. 1C). Thus, pterostilbene has a more efficacious antiviral effect at lower concentrations in comparison to resveratrol.

Next, we investigated how long resveratrol and pterostilbene maintain their antiviral activity in cell culture. We infected Vero E6 cells with SARS-CoV-2 at MOI 0.01 in the presence of the compound and harvested the supernatant at 16, 24, 40, $60 \mathrm{hrs}$ post-inoculation (hpi). For the non-treated (NT) and solvent control samples, no differences were observed in virus growth and virus particle production plateaued at 40 hpi at which time point all cells were dead (Fig. $1 \mathrm{D}, \mathrm{E})$. In the presence of resveratrol as well as pterostilbene a strong antiviral effect $(\sim 2 \log$ reduction which corresponds to $99 \%$ reduction in virus production) was observed at 16 and 24 hpi. Significant antiviral activity was observed up to 40 hpi. Thus, without replenishment of the compound an antiviral effect is seen up to 5 rounds of replication, since 1 round of replication is approximately $8 \mathrm{hr}$ (19). These findings highlight the long-lasting in vitro antiviral effect of both compounds. 

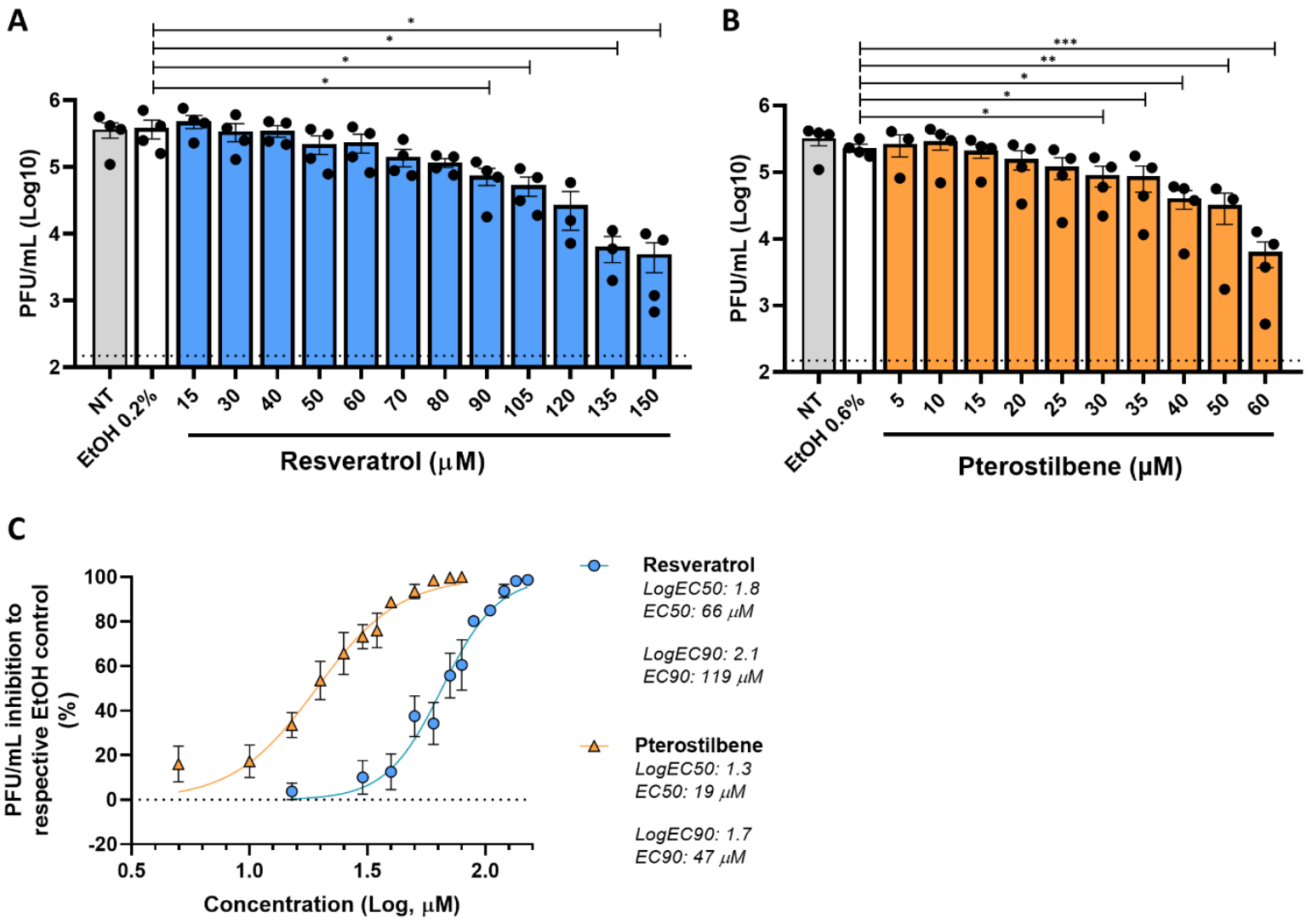

D

$$
\begin{aligned}
& \text { 口 NT } \\
& \text { 口 EtOH } 0.2 \% \\
& \text { 口 Resveratrol }
\end{aligned}
$$

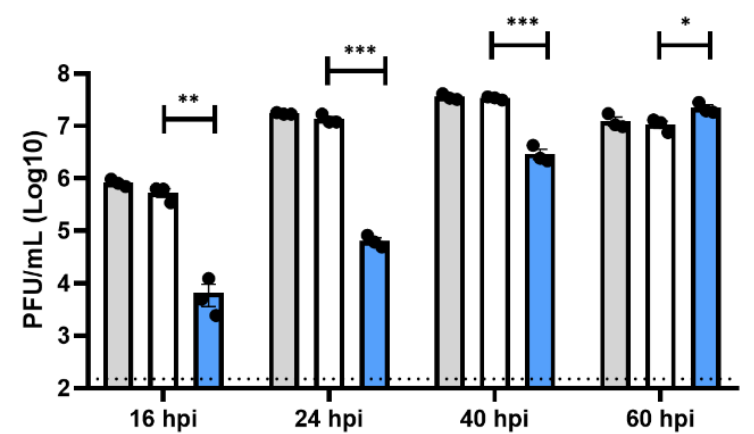

E

$$
\begin{aligned}
& \text { 口 NT } \\
& \text { 口 EtOH 0.6\% } \\
& \text { ロ Pterostilbene }
\end{aligned}
$$

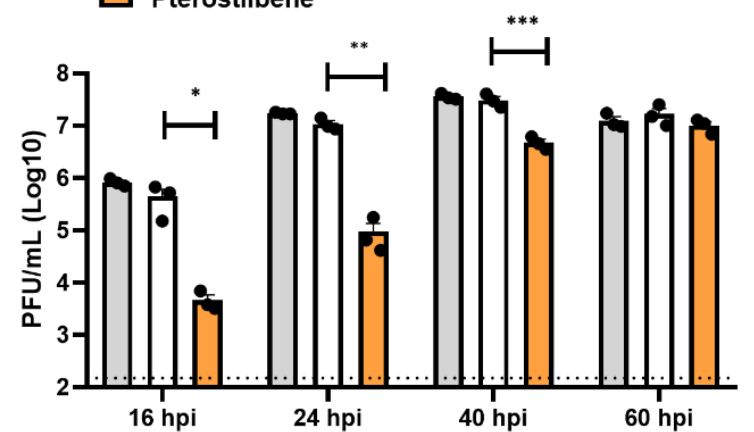

Figure 1. Antiviral effect of resveratrol and pterostilbene towards SARS-CoV-2 in Vero E6 cells. Production of infectious virus particles by Vero E6 cells inoculated with SARS-CoV-2 at MOI 1 in the absence (NT denotes for non-treated) or presence of increasing concentrations of (A) resveratrol, (B) pterostilbene or (A,B) the EtOH solvent control. (C) The EC50 and EC90 values determined by non-linear regression analysis. (D,E) Durability of the antiviral effect of (D) resveratrol and (E) pterostilbene at 16, 24, 40 and 60 hpi. Dotted line indicates the threshold of detection. Data are represented as mean \pm SEM of at least three independent experiments. Each symbol represents data from a single independent experiment. Student $\mathrm{T}$ test was used to evaluate statistical differences and a $\mathrm{p}$ value $\leq 0.05$ was considered significant with $* \mathrm{p} \leq 0.05,{ }^{* *} \mathrm{p} \leq 0.01$ and $* * * \mathrm{p} \leq 0.001$. 


\section{Resveratrol and pterostilbene directly interfere with SARS-CoV-2 replication.}

To test whether the antiviral capacity of the compounds rely on lysis, inactivation or neutralization of the virion itself, we next performed a virucidal assay (20). Briefly, $2.5 \times 10^{5}$ PFU of SARS-CoV-2 was incubated with $150 \mu \mathrm{M}$ resveratrol, $60 \mu \mathrm{M}$ pterostilbene or equivalent volumes of $\mathrm{EtOH}$ for $2 \mathrm{hr}$ and subjected to plaque assay. No differences in viral titers were observed relative to the NT or EtOH control (Fig. 2A). This indicates that the compounds do not exhibit virucidal activity at these conditions, but rather interfere with viral replication in Vero E6 cells. To examine this further, we performed a time-of-drug-addition experiment. In this experiment, resveratrol or pterostilbene was added either prior, during or post SARS-CoV2 inoculation and infectious virus particle production was evaluated at 8 hpi (Fig. 2B). Comparable results were obtained for both compounds (Fig. 2C,D). No effect was observed when the compounds were solely present prior to inoculation. A mild, yet non-significant, reduction in virus particle production was observed when the compounds were present during virus inoculation. Importantly, a significant reduction in virus particle production was observed when the compounds were added after removal of the virus inoculum (Fig. 2C,D). No significant effect was noted when resveratrol or pterostilbene were added at 4 or 6 hpi (Fig. S2A,B). Collectively, these results indicate that the compounds directly interfere with the virus replication cycle at a stage after virus entry but prior to virus assembly and release.

A

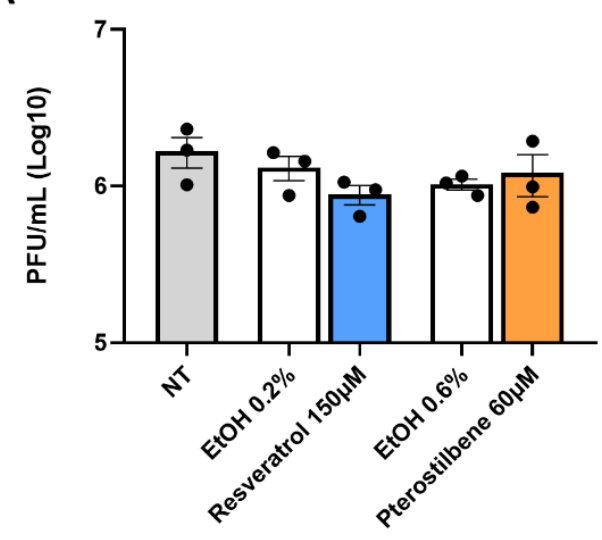

B

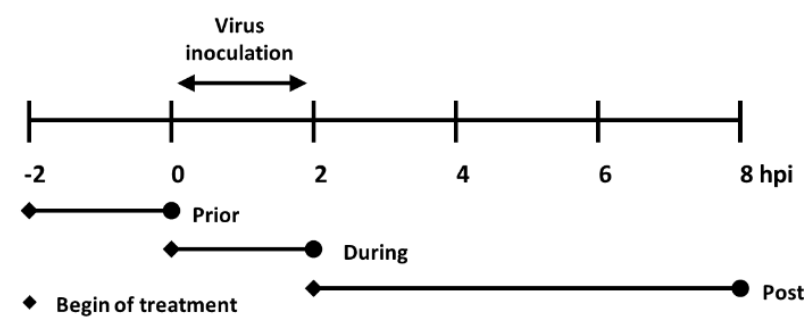

- End of treatment
C

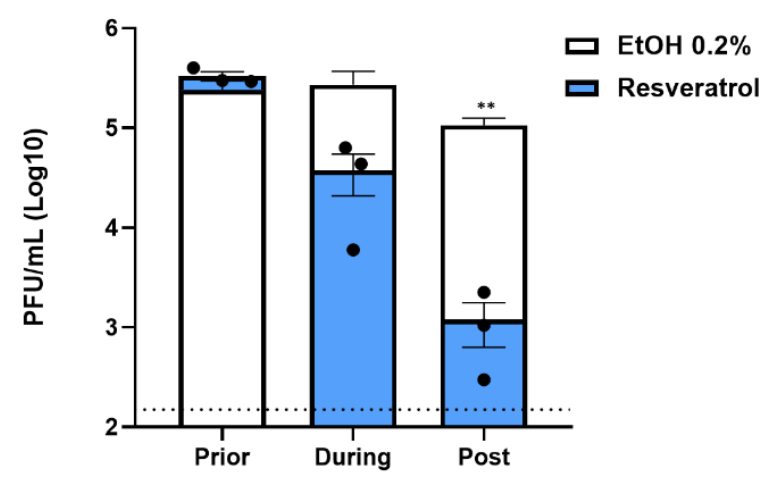

D

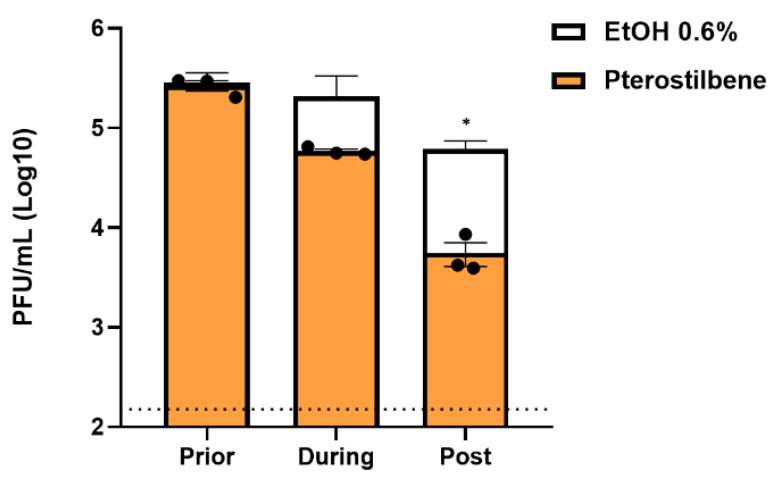

Figure 2. Resveratrol and pterostilbene interfere with SARS-CoV-2 infection when added post virus inoculation conditions. (A) Virucidal effect of resveratrol and pterostilbene on SARS-CoV-2. (B) Schematic 
representation of the experimental design of the time-of-drug-addition assay. Vero E6 cells were inoculated with SARS-CoV-2 at MOI 1 and treated with (C) $150 \mu \mathrm{M}$ resveratrol, (D) $60 \mu \mathrm{M}$ pterostilbene or (C,D) equivalent volumes of EtOH. Virus production was determined at $8 \mathrm{hpi}$ via plaque assay. Data is represented as mean $\pm \mathrm{SEM}$ from three independent experiments. Dotted line indicates the threshold of detection. Student $\mathrm{T}$ test was used to evaluate statistical differences and a $\mathrm{p}$ value $\leq 0.05$ was considered significant with $* \mathrm{p} \leq 0.05, * * \mathrm{p} \leq 0.01$ and $* * * \mathrm{p}$ $\leq 0.001$ and NS as non-significant.

\section{Resveratrol and pterostilbene do not exhibit significant anti-SARS-CoV-2 activity in Calu-3 cells.}

We next sought to verify the findings in the human lung epithelial cell model, Calu-3 cells (21). Resveratrol was more cytotoxic in Calu-3 cells when compared to Vero E6, since the highest non-toxic concentration was $50 \mu \mathrm{M}$ (Fig. S3A) At this concentration, no antiviral effect was seen in Vero E6 cells. For pterostilbene, the highest non-toxic concentration was set at $60 \mu \mathrm{M}$, similar to Vero E6 cells (Fig. S3B). At these concentrations, no significant reduction in virus particle production was observed with both compounds in Calu-3 cells (Fig. 3A,B) although a negative trend in virus particle production was observed with pterostilbene. The inability of both compounds to induce antiviral effects in Calu-3 as observed in Vero E6, could underline the inherent differences between these two cell line models.

A

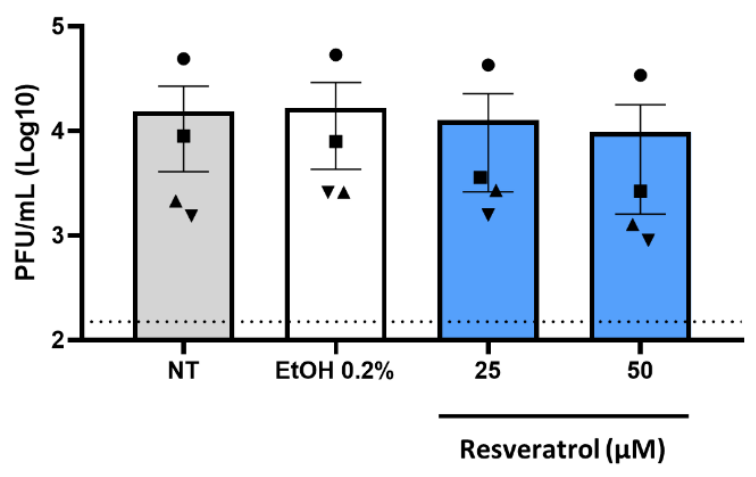

B

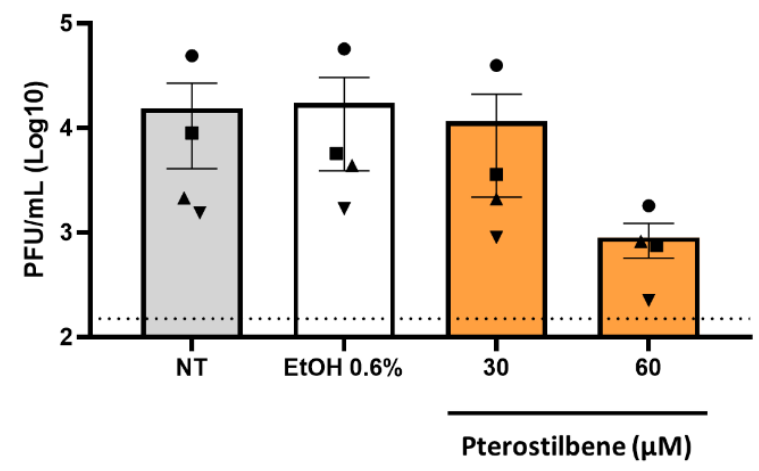

Figure 3. Resveratrol and pterostilbene do not significantly inhibit SARS-CoV-2 infection in Calu-3 cells. Calu-3 cells were inoculated with SARS-CoV-2 in the absence (non-treated, NT) or presence of (A) 25 or $50 \mu \mathrm{M}$ resveratrol, (B) 30 or $60 \mu \mathrm{M}$ pterostilbene, or (A,B) the equivalent volumes of EtOH. Virus particle production was determined at 8 hpi by plaque assay. Data is represented as mean \pm SEM from three independent experiments. Dotted line indicates the threshold of detection. Student $T$ test was used to evaluate statistical differences and a $\mathrm{p}$ value $\leq 0.05$ was considered significant with $* \mathrm{p} \leq 0.05,{ }^{* *} \mathrm{p} \leq 0.01$ and ${ }^{* * *} \mathrm{p} \leq 0.001$.

\section{Resveratrol and pterostilbene significantly inhibit SARS-CoV-2 infection in primary human bronchial epithelial cells cultured under ALI conditions.}

Given the known variability of data obtained in SARS-CoV-2 cell line models (21), we decided to also verify the antiviral activity of resveratrol and pterostilbene in a primary human bronchial epithelial cell (PBEC) model $(22,23)$. PBECs obtained from healthy individuals, were cultured on ALI conditions to induce differentiation into ciliated and secretory epithelial cells (24) (Fig. 4A). 


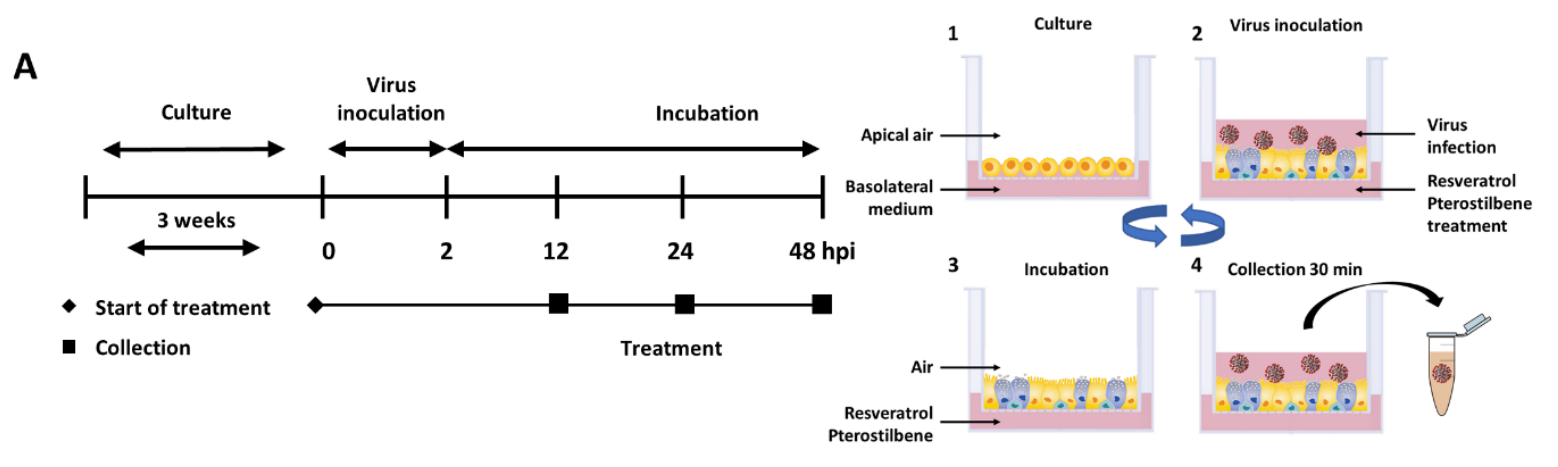

B
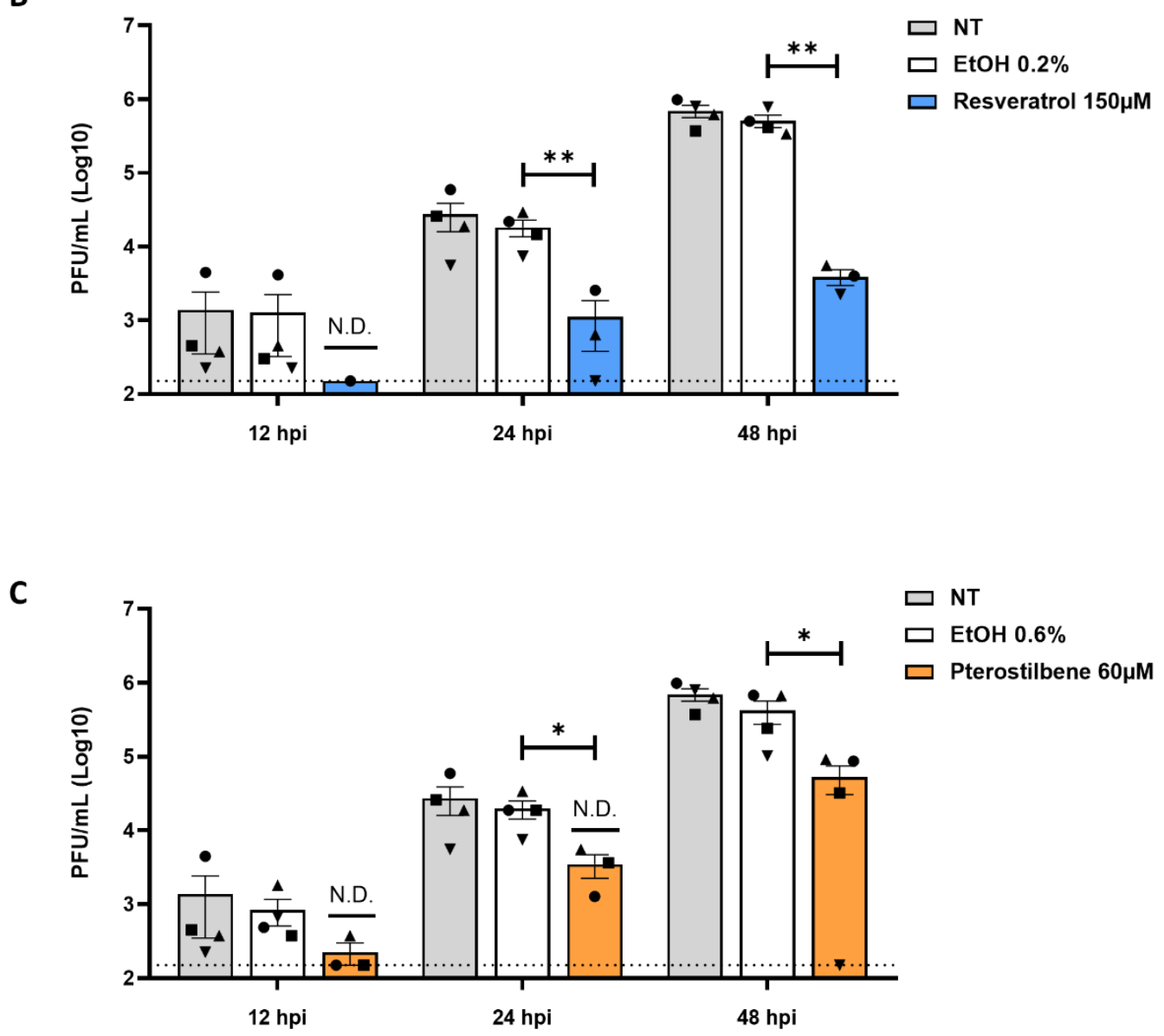

Figure 4. Resveratrol and pterostilbene inhibit SARS-CoV-2 infection in primary human bronchial epithelial cells. (A) Schematic representation of the experimental design. (1) Primary human bronchial epithelial cells (PBECs) were cultured on permeable inserts under Air Liquid Interface (ALI) conditions for 21 days. (2) Cells were inoculated with SARS-CoV-2 MOI 5 at the apical side. (3) At 2 hpi, the virus inoculum was removed and cells were exposed to air until virus collection. (4) Medium was added to the apical side and collected after 30 min incubation. After supernatant collection, PBECs were exposed to air again (3) until the next collection time point. Step $\mathbf{4}$ and $\mathbf{3}$ were repeated until the end of the experiment. (B,C) Virus particle production in PBECs in presence of (B) resveratrol or (C) pterostilbene. Scheme adapted from STEMCELL Technologies Data is represented as mean \pm SEM from three or four different donors. Dotted line indicates the threshold of detection. Student $T$ test was used to evaluate statistical differences and a $p$ value $\leq 0.05$ was considered significant with * $p$ $\leq 0.05, * * \mathrm{p} \leq 0.01$ and $* * * \mathrm{p} \leq 0.001$. 
In this model, no cytotoxicity was found at a concentration of $150 \mu \mathrm{M}$ resveratrol and $60 \mu \mathrm{M}$ pterostilbene as determined by live/death staining using flow cytometry and by a LDH assay (Fig. S4A,B). Accordingly, fully differentiated PBECs were inoculated with SARS-CoV-2 (MOI 5) in the presence of resveratrol and pterostilbene, and progeny virus particle production was evaluated at 12, 24, 48 hpi (Fig. 4A). At $12 \mathrm{hpi}$, the viral titers were very low and in presence of the compounds often fell below the threshold of detection (Fig. 4B,C). Importantly, at 24 and $48 \mathrm{hpi}$, a significant antiviral effect was observed for both resveratrol and pterostilbene (Fig. 4B,C). At $48 \mathrm{hpi}$, the virus titer was significantly reduced with $2.1 \mathrm{Log}$ (corresponding to 99.3\% reduction) when compared to the EtOH control in PBECs treated with resveratrol. In presence of pterostilbene, the virus titer was reduced with $1.2 \mathrm{Log}$ (corresponding to 87,5\% reduction) when compared to the EtOH control in PBECs at 48 hpi. Collectively, our data demonstrate that resveratrol and pterostilbene exhibit potent antiviral activity towards SARSCoV-2 in differentiated human PBECs.

\section{Discussion}

Based on our data we conclude that both resveratrol and pterostilbene have the potential to exhibit antiviral efficacy early in the course of COVID-19. Resveratrol or pterostilbene strongly reduced SARS-CoV-2 production not only in Vero-E6 cells but also in the biologically highly relevant primary human bronchial epithelial cell model. Moreover, we show that both compounds actively interfere with virus replication and, without replenishment of the compound, exert antiviral activity up to roughly 5 replication cycles of SARS-CoV-2 in vitro.

Resveratrol and pterostilbene share many biological functions (25) and in this study comparable results were obtained for both compounds as well. Time-of-drug-addition experiments revealed that resveratrol and pterostilbene strongly inhibited SARS-CoV-2 production when administered after removal of the virus inoculum, suggesting that they both act after virus entry into the host cells. Furthermore, addition of compounds at 4 hpi did not lead to a major reduction in virus progeny suggesting that the compounds most likely interfere with early steps of genome translation and/or viral RNA (vRNA) replication and/or viral protein synthesis. These results are in line with the antiviral activity of resveratrol against other viruses. For example, resveratrol inhibited influenza virus replication and viral protein synthesis via interference with nuclear-cytoplasmic transport of vRNA and the inhibition of protein kinase C activity (8). Resveratrol also decreased viral gene expression and viral protein synthesis of Herpes Simplex Virus and Epstein-Barr virus (26-28). Future studies should delineate the in-depth mode-ofaction of resveratrol and pterostilbene in controlling SARS-CoV-2 infection.

Next to the direct antiviral properties on SARS-CoV-2 replication, resveratrol might also be suitable to moderate the exacerbated inflammatory response observed in COVID-19 patients (29). Resveratrol has been shown to have anti-inflammatory properties thereby reducing the release of pro-inflammatory cytokines (9,30-32). Secondly, as an antioxidant, resveratrol is found to prevent the formation of reactive oxygen species (ROS), prevent airway epithelial remodeling by upregulation of SIRT1 and activate superoxide dismutase (SOD) $(33,34)$. Lastly, resveratrol reduces the secretion of leptin (35), an adipokine that has been implicated to be a contributing factor in the development of respiratory failure and ARDS in SARS-CoV-2 infected patients (15). Therefore, resveratrol might not only be a promising candidate to inhibit viral replication early in infection it may also alleviate disease symptoms later in infection. 
Pterostilbene was found more effective in controlling SARS-CoV-2 replication than resveratrol at low concentrations. Indeed, many in vitro and animal studies have revealed that pterostilbene is superior to resveratrol. This has been linked to the dimethoxy structure in pterostilbene which increases lipophilicity and restricts glucuronidation and sulfation hence improving the solubility, absorption and bioavailability of the compound (36). In healthy volunteers, oral administration of both compounds is considered safe at doses up to 5 gram per day for resveratrol and $250 \mathrm{mg}$ per day for pterostilbene $(37,38)$. However, the bioavailability of resveratrol is low as plasma concentrations in the nanomolar range were achieved $(39,40)$. The pharmacokinetics of pterostilbene has not been investigated in humans and given its favorable characteristics and potent antiviral activity towards SARS-CoV-2 infection this is highly warranted.

Comparable to other respiratory viruses, potent antiviral activity towards SARS-CoV-2 is seen at relatively high concentrations of resveratrol. Due to the low bioavailability of resveratrol upon oral administration, it is unlikely that an effective antiviral dose towards respiratory viruses can be achieved in humans via this route of administration. Therefore, other administration modes and routes have been explored. Promising strategies for antiviral treatment are the use of aerosolized suspension sprays of resveratrol, co-spray dried microparticles or nanotechnology approaches (e.g nanoparticles, nanosponges) (41-43). Although not yet tested, these strategies might also further enhance the potency of pterostilbene. Adjacent to the improved bioavailability, some of these techniques allow drug directed and local delivery of resveratrol or pterostilbene to the primary site of active SARS-CoV-2 replication using inhalation-based systems, which are currently considered as a favorable future strategy for the treatment of COVID-19 (44).

Finally, since both drugs are commercially available and could therefore be used as a selfmedicative prophylactic, a word of caution must be considered. Our data represent promising laboratory findings in cells, and therefore do not indicate that these drugs will be of benefit to treat COVID-19 in patients. Randomized double-blind controlled clinical trials must first swiftly be conducted to prove whether or not these drugs are indeed advantageous for COVID19 treatment.

\section{Acknowledgements}

The authors thank dr. Y. Bhide for help in the design of experiments and prof. dr. H. van Goor for fruitful discussions. Grant support was provided by ZonMw, project nr: 10430012010006 and the University Medical Center of Groningen. B.M.E., N.D.K, E.M.B, M.C.N, P.V., J.M., I.A.R.Z. and J.M.S designed the experiments. B.M.E., N.D.K, E.M.B, B.T., D.P.I.P., H.H.E., L.A., D.G., executed the experiments. M.B. selected and recruited donors, sampled donors, and analyzed donor data. B.M.E, E.M.B. I.A.R.Z and J.M.S wrote the manuscript. All authors edited the manuscript. 


\section{References}

(1) John Hopkins university and medicine https://coronavirus.jhu.edu/ (accessed Nov 19, 2020).

(2) Tay, M. Z.; Poh, C. M.; Rénia, L.; MacAry, P. A.; Ng, L. F. P. The Trinity of COVID19: Immunity, Inflammation and Intervention. Nat. Rev. Immunol. 2020, 20 (6), $363-$ 374. https://doi.org/10.1038/s41577-020-0311-8.

(3) Wong, C. K.; Lam, C. W. K.; Wu, A. K. L.; Ip, W. K.; Lee, N. L. S.; Chan, I. H. S.; Lit, L. C. W.; Hui, D. S. C.; Chan, M. H. M.; Chung, S. S. C.; Sung, J. J. Y. Plasma Inflammatory Cytokines and Chemokines in Severe Acute Respiratory Syndrome. Clin. Exp. Immunol. 2004, 136 (1), 95-103. https://doi.org/10.1111/j.13652249.2004.02415.x.

(4) Grant, R. A.; Morales-Nebreda, L.; Markov, N. S.; Swaminathan, S.; Guzman, E. R.; Abbott, D. A.; Donnelly, H. K.; Donayre, A.; Goldberg, I. A.; Klug, Z. M.; Borkowski, N.; Lu, Z.; Kihshen, H.; Politanska, Y.; Sichizya, L.; Kang, M.; Shilatifard, A.; Qi, C.; Argento, A. C.; Kruser, J. M.; Malsin, E. S.; Pickens, C. O.; Smith, S.; Walter, J. M.; Pawlowski, A. E.; Schneider, D.; Nannapaneni, P.; Abdala-Valencia, H.; Bharat, A.; Gottardi, C. J.; Budinger, G. R. S.; Misharin, A. V.; Singer, B. D.; Wunderink, R. G.; Investigators, T. N. S. S. Alveolitis in Severe SARS-CoV-2 Pneumonia Is Driven by Self-Sustaining Circuits between Infected Alveolar Macrophages and T Cells. bioRxiv 2020. https://doi.org/10.1101/2020.08.05.238188.

(5) Wang, P.; Sang, S. Metabolism and Pharmacokinetics of Resveratrol and Pterostilbene. BioFactors 2018, 44 (1), 16-25. https://doi.org/10.1002/biof.1410.

(6) Tsai, H. Y.; Ho, C. T.; Chen, Y. K. Biological Actions and Molecular Effects of Resveratrol, Pterostilbene, and 3'-Hydroxypterostilbene. J. Food Drug Anal. 2017, 25 (1), 134-147. https://doi.org/10.1016/j.jfda.2016.07.004.

(7) Chan, C. N.; Trinité, B.; Levy, D. N. Potent Inhibition of HIV-1 Replication in Resting CD4 T Cells by Resveratrol and Pterostilbene. Antimicrob. Agents Chemother. 2017, 61 (9), e00408-17. https://doi.org/10.1128/AAC.00408-17.

(8) Palamara, A. T.; Nencioni, L.; Aquilano, K.; De Chiara, G.; Hernandez, L.; Cozzolino, F.; Ciriolo, M. R.; Garaci, E. Inhibition of Influenza A Virus Replication by Resveratrol. J. Infect. Dis. 2005, 191 (10), 1719-1729. https://doi.org/10.1086/429694.

(9) Xie, X. H.; Zang, N.; Li, S. min; Wang, L. jia; Deng, Y.; He, Y.; Yang, X. qiang; Liu, E. mei. Resveratrol Inhibits Respiratory Syncytial Virus-Induced IL-6 Production, Decreases Viral Replication, and Downregulates TRIF Expression in Airway Epithelial Cells. Inflammation 2012, 35 (4), 1392-1401. https://doi.org/10.1007/s10753-0129452-7.

(10) Lin, S. C.; Ho, C. T.; Chuo, W. H.; Li, S.; Wang, T. T.; Lin, C. C. Effective Inhibition of MERS-CoV Infection by Resveratrol. BMC Infect. Dis. 2017, 144, 17:144. https://doi.org/10.1186/s12879-017-2253-8.

(11) Filardo, S.; Di Pietro, M.; Mastromarino, P.; Sessa, R. Therapeutic Potential of Resveratrol against Emerging Respiratory Viral Infections. Pharmacol. Ther. 2020, 214, 107613. https://doi.org/10.1016/j.pharmthera.2020.107613.

(12) Zhu, X. D.; Lei, X. P.; Dong, W. Bin. Resveratrol as a Potential Therapeutic Drug for 
bioRxiv preprint doi: https://doi.org/10.1101/2020.09.24.285940; this version posted February 2, 2021. The copyright holder for this

Respiratory System Diseases. Drug Des. Devel. Ther. 2017, 11, 3591-3598. https://doi.org/10.2147/DDDT.S148868.

(13) Horne, J. R.; Vohl, M. C. Biological Plausibility for Interactions between Dietary Fat, Resveratrol, ACE2, and SARS-CoV Illness Severity. Am. J. Physiol. - Endocrinol. Metab. 2020, 318 (5), E830-E833. https://doi.org/10.1152/AJPENDO.00150.2020.

(14) Marinella, M. A. Indomethacin and Resveratrol as Potential Treatment Adjuncts for SARS-CoV-2/COVID-19. Int. J. Clin. Pract. 2020, 74 (9), e13535. https://doi.org/10.1111/ijcp.13535.

(15) van der Voort, P. H.; Moser, J.; Zandstra, D. F.; Muller Kobold, A. C.; Knoester, M.; Calkhoven, C. F.; Hamming, I.; van Meurs, M. Leptin Levels in SARS-CoV-2 Infection Related Respiratory Failure: A Cross-Sectional Study and a Pathophysiological Framework on the Role of Fat Tissue. Heliyon 2020, 6 (8), e04696. https://doi.org/10.1016/j.heliyon.2020.e04696.

(16) Vieira Braga, F. A.; Kar, G.; Berg, M.; Carpaij, O. A.; Polanski, K.; Simon, L. M.; Brouwer, S.; Gomes, T.; Hesse, L.; Jiang, J.; Fasouli, E. S.; Efremova, M.; VentoTormo, R.; Talavera-López, C.; Jonker, M. R.; Affleck, K.; Palit, S.; Strzelecka, P. M.; Firth, H. V.; Mahbubani, K. T.; Cvejic, A.; Meyer, K. B.; Saeb-Parsy, K.; Luinge, M.; Brandsma, C. A.; Timens, W.; Angelidis, I.; Strunz, M.; Koppelman, G. H.; van Oosterhout, A. J.; Schiller, H. B.; Theis, F. J.; van den Berge, M.; Nawijn, M. C.; Teichmann, S. A. A Cellular Census of Human Lungs Identifies Novel Cell States in Health and in Asthma. Nat. Med. 2019, 25 (7), 1153-1163. https://doi.org/10.1038/s41591-019-0468-5.

(17) Heijink, I. H.; Kies, P. M.; Kauffman, H. F.; Postma, D. S.; van Oosterhout, A. J. M.; Vellenga, E. Down-Regulation of E-Cadherin in Human Bronchial Epithelial Cells Leads to Epidermal Growth Factor Receptor-Dependent Th2 Cell-Promoting Activity. J. Immunol. 2007, 178 (12), 7678-7685. https://doi.org/10.4049/jimmunol.178.12.7678.

(18) Heijink, I. H.; Postma, D. S.; Noordhoek, J. A.; Broekema, M.; Kapus, A. House Dust Mite-Promoted Epithelial-to-Mesenchymal Transition in Human Bronchial Epithelium. Am. J. Respir. Cell Mol. Biol. 2010, 42 (1), 69-79. https://doi.org/10.1165/rcmb.200804490C.

(19) Ogando, N. S.; Dalebout, T. J.; Zevenhoven-Dobbe, J. C.; Limpens, R. W. A. L.; van der Meer, Y.; Caly, L.; Druce, J.; de Vries, J. J. C.; Kikkert, M.; Bárcena, M.; Sidorov, I.; Snijder, E. J. SARS-Coronavirus-2 Replication in Vero E6 Cells: Replication Kinetics, Rapid Adaptation and Cytopathology. J. Gen. Virol. 2020, 101, 925-940. https://doi.org/10.1099/jgv.0.001453.

(20) Troost, B.; Mulder, L. M.; Diosa-Toro, M.; van de Pol, D.; Rodenhuis-Zybert, I. A.; Smit, J. M. Tomatidine, a Natural Steroidal Alkaloid Shows Antiviral Activity towards Chikungunya Virus in Vitro. Sci. Rep. 2020, 10 (1), 6364. https://doi.org/10.1038/s41598-020-63397-7.

(21) Chu, H.; Chan, J. F.-W.; Yuen, T. T.-T.; Shuai, H.; Yuan, S.; Wang, Y.; Hu, B.; Yip, C. C.-Y.; Tsang, J. O.-L.; Huang, X.; Chai, Y.; Yang, D.; Hou, Y.; Chik, K. K.-H.; Zhang, X.; Fung, A. Y.-F.; Tsoi, H.-W.; Cai, J.-P.; Chan, W.-M.; Ip, J. D.; Chu, A. W.H.; Zhou, J.; Lung, D. C.; Kok, K.-H.; To, K. K.-W.; Tsang, O. T.-Y.; Chan, K.-H.; Yuen, K.-Y. Comparative Tropism, Replication Kinetics, and Cell Damage Profiling of 
SARS-CoV-2 and SARS-CoV with Implications for Clinical Manifestations, Transmissibility, and Laboratory Studies of COVID-19: An Observational Study. The Lancet Microbe 2020, 1 (1), e14-e23. https://doi.org/10.1016/s2666-5247(20)30004-5.

(22) Heijink, I. H.; De Bruin, H. G.; Dennebos, R.; Jonker, M. R.; Noordhoek, J. A.; Brandsma, C. A.; Van Den Berge, M.; Postma, D. S. Cigarette Smoke-Induced Epithelial Expression of WNT-5B: Implications for COPD. Eur. Respir. J. 2016, 48 (2), 504-515. https://doi.org/10.1183/13993003.01541-2015.

(23) Ravindra, N.; Alfajaro, M. M.; Gasque, V.; Habet, V.; Wei, J.; Filler, R.; Huston, N.; Wan, H.; Szigeti-Buck, K.; Wang, B.; Wang, G.; Montgomery, R.; Eisenbarth, S.; Williams, A.; Pyle, A. M.; Iwasaki, A.; Horvath, T.; Foxman, E.; Pierce, R.; van Dijk, D.; Wilen, C. Single-Cell Longitudinal Analysis of SARS-CoV-2 Infection in Human Airway Epithelium. bioRxiv Prepr. Serv. Biol. 2020. https://doi.org/10.1101/2020.05.06.081695.

(24) Tellez, G. F.; Willemse, B. W. M.; Brouwer, U.; Brinksma, S. N.; Vandepoele, K.; Noordhoek, J. A.; Heijink, I.; De Vries, M.; Smithers, N. P.; Postma, D. S.; Timens, W.; Wiffen, L.; Van Roy, F.; Holloway, J. W.; Lackie, P. M.; Nawijn, M. C.;

Koppelman, G. H. Protocadherin-1localizationand Celladhesionfunction in Airway Epithelialcells in Asthma. PLoS One 2016, 11 (10), e0163967. https://doi.org/10.1371/journal.pone.0163967.

(25) McCormack, D.; McFadden, D. A Review of Pterostilbene Antioxidant Activity and Disease Modification. Oxid. Med. Cell. Longev. 2013, 2013 (575482). https://doi.org/10.1155/2013/575482.

(26) Docherty, J. J.; Fu, M. M. H.; Stiffler, B. S.; Limperos, R. J.; Pokabla, C. M.; Delucia, A. L. Resveratrol Inhibition of Herpes Simplex Virus Replication. Antiviral Res. 1999, 43, 135-145. https://doi.org/10.1016/S0166-3542(99)00042-X.

(27) Yiu, C. Y.; Chen, S. Y.; Chang, L. K.; Chiu, Y. F.; Lin, T. P. Inhibitory Effects of Resveratrol on the Epstein-Barr Virus Lytic Cycle. Molecules 2010, 15 (10), 71157124. https://doi.org/10.3390/molecules15107115.

(28) De Leo, A.; Arena, G.; Lacanna, E.; Oliviero, G.; Colavita, F.; Mattia, E. Resveratrol Inhibits Epstein Barr Virus Lytic Cycle in Burkitt's Lymphoma Cells by Affecting Multiple Molecular Targets. Antiviral Res. 2012, 96 (2), 196-202. https://doi.org/10.1016/j.antiviral.2012.09.003.

(29) Qin, C.; Zhou, L.; Hu, Z.; Zhang, S.; Yang, S.; Tao, Y.; Xie, C.; Ma, K.; Shang, K.; Wang, W.; Tian, D. S. Dysregulation of Immune Response in Patients with Coronavirus 2019 (COVID-19) in Wuhan, China. Clin. Infect. Dis. 2020, 71 (15), 762768. https://doi.org/10.1093/cid/ciaa248.

(30) Kim, M. H.; Yoo, D. S.; Lee, S. Y.; Byeon, S. E.; Lee, Y. G.; Min, T.; Rho, H. S.; Rhee, M. H.; Lee, J.; Cho, J. Y. The TRIF/TBK1/IRF-3 Activation Pathway Is the Primary Inhibitory Target of Resveratrol, Contributing to Its Broad-Spectrum AntiInflammatory Effects. Pharmazie 2011, 66 (4), 296-300. https://doi.org/10.1691/ph.2011.0798.

(31) Liu, T.; Zang, N.; Zhou, N.; Li, W.; Xie, X.; Deng, Y.; Ren, L.; Long, X.; Li, S.; Zhou, L.; Zhao, X.; Tu, W.; Wang, L.; Tan, B.; Liu, E. Resveratrol Inhibits the TRIFDependent Pathway by Upregulating Sterile Alpha and Armadillo Motif Protein, 
bioRxiv preprint doi: https://doi.org/10.1101/2020.09.24.285940; this version posted February 2, 2021. The copyright holder for this preprint (which was not certified by peer review) is the author/funder. All rights reserved. No reuse allowed without permission.

Contributing to Anti-Inflammatory Effects after Respiratory Syncytial Virus Infection. J. Virol. 2014, 88 (8), 4229-4236. https://doi.org/10.1128/jvi.03637-13.

(32) Youn, H. S.; Lee, J. Y.; Fitzgerald, K. A.; Young, H. A.; Akira, S.; Hwang, D. H. Specific Inhibition of MyD88-Independent Signaling Pathways of TLR3 and TLR4 by Resveratrol: Molecular Targets Are TBK1 and RIP1 in TRIF Complex. J. Immunol. 2005, 175 (5), 3339-3346. https://doi.org/10.4049/jimmunol.175.5.3339.

(33) Liu, H.; Ren, J.; Chen, H.; Huang, Y.; Li, H.; Zhang, Z.; Wang, J. Resveratrol Protects against Cigarette Smoke-Induced Oxidative Damage and Pulmonary Inflammation. $J$. Biochem. Mol. Toxicol. 2014, 28 (10), 465-471. https://doi.org/10.1002/jbt.21586.

(34) Wang, X. L.; Li, T.; Li, J. H.; Miao, S. Y.; Xiao, X. Z. The Effects of Resveratrol on Inflammation and Oxidative Stress in a Rat Model of Chronic Obstructive Pulmonary Disease. Molecules 2017, 22 (9), 1529. https://doi.org/10.3390/molecules22091529.

(35) Szkudelska, K.; Nogowski, L.; Szkudelski, T. The Inhibitory Effect of Resveratrol on Leptin Secretion from Rat Adipocytes. Eur. J. Clin. Invest. 2009, 39 (10), 899-905. https://doi.org/10.1111/j.1365-2362.2009.02188.x.

(36) Nagao, K.; Jinnouchi, T.; Kai, S.; Yanagita, T. Pterostilbene, a Dimethylated Analog of Resveratrol, Promotes Energy Metabolism in Obese Rats. J. Nutr. Biochem. 2017, 43, 151-155. https://doi.org/10.1016/j.jnutbio.2017.02.009.

(37) Brown, V. A.; Patel, K. R.; Viskaduraki, M.; Crowell, J. A.; Perloff, M.; Booth, T. D.; Vasilinin, G.; Sen, A.; Schinas, A. M.; Piccirilli, G.; Brown, K.; Steward, W. P.; Gescher, A. J.; Brenner, D. E. Repeat Dose Study of the Cancer Chemopreventive Agent Resveratrol in Healthy Volunteers: Safety, Pharmacokinetics, and Effect on the Insulin-like Growth Factor Axis. Cancer Res. 2010, 70 (22), 9003-9011. https://doi.org/10.1158/0008-5472.CAN-10-2364.

(38) Riche, D. M.; McEwen, C. L.; Riche, K. D.; Sherman, J. J.; Wofford, M. R.; Deschamp, D.; Griswold, M. Analysis of Safety from a Human Clinical Trial with Pterostilbene. J. Toxicol. 2013, 2013, 463595. https://doi.org/10.1155/2013/463595.

(39) Walle, T.; Hsieh, F.; DeLegge, M. H.; Oatis, J. E.; Walle, U. K. High Absorption but Very Low Bioavailability of Oral Resveratrol in Humans. Drug Metab. Dispos. 2004, 32 (12), 1377-1382. https://doi.org/10.1124/dmd.104.000885.

(40) Boocock, D. J.; Faust, G. E. S.; Patel, K. R.; Schinas, A. M.; Brown, V. A.; Ducharme, M. P.; Booth, T. D.; Crowell, J. A.; Perloff, M.; Gescher, A. J.; Steward, W. P.; Brenner, D. E. Phase I Dose Escalation Pharmacokinetic Study in Healthy Volunteers of Resveratrol, a Potential Cancer Chemopreventive Agent. Cancer Epidemiol. Biomarkers Prev. 2007, 16 (6), 1246-1252. https://doi.org/10.1158/1055-9965.EPI-070022.

(41) Trotta, V.; Lee, W. H.; Loo, C. Y.; Young, P. M.; Traini, D.; Scalia, S. Co-Spray Dried Resveratrol and Budesonide Inhalation Formulation for Reducing Inflammation and Oxidative Stress in Rat Alveolar Macrophages. Eur. J. Pharm. Sci. 2016, 86, 20-28. https://doi.org/10.1016/j.ejps.2016.02.018.

(42) Dhakar, N. K.; Matencio, A.; Caldera, F.; Argenziano, M.; Cavalli, R.; Dianzani, C.; Zanetti, M.; López-Nicolás, J. M.; Trotta, F. Comparative Evaluation of Solubility, Cytotoxicity and Photostability Studies of Resveratrol and Oxyresveratrol Loaded Nanosponges. Pharmaceutics 2019, 11 (10), 545. 
https://doi.org/10.3390/pharmaceutics11100545.

(43) Lv, C.; Zhang, Y.; Shen, L. Preliminary Clinical Effect Evaluation of Resveratrol in Adults with Allergic Rhinitis. Int. Arch. Allergy Immunol. 2018, 175 (4), 231-236. https://doi.org/10.1159/000486959.

(44) Sahakijpijarn, S.; Moon, C.; Koleng, J. J.; Williams Iii, R. O. Development of Remdesivir as a Dry Powder for Inhalation by Thin Film Freezing. Pharmaceutics 2020, 2020 (12), 1002. 